\title{
Flexural Strength of Single Polymer Polyester Composites as a Measure of Material Degradation
}

\author{
KATARZYNA GAWDZINSKA*, MARCIN NABIALEK², KATARZYNA BRYLL', PAWEL SZYMANSKI ${ }^{3}$, ANDREI VICTOR SANDU4,5 \\ ${ }^{1}$ Department of Shipbuilding Materials Engineering, Faculty of Marine Engineering, Maritime University of Szczecin, Willowa 2- \\ 4, 71-650 Szczecin, Poland \\ ${ }^{2}$ Institute of Physics, Faculty of Production Engineering and Materials Technology, Czestochowa University of Technology, Armii \\ Krajowej 19, 42-200 Czestochowa, Poland \\ ${ }^{3}$ Institute of Materials Technology, Poznan University of Technology, Piotrowo 3, 60-965 Poznan, Poland \\ ${ }^{4}$ Gheorghe Asachi Technical University of lasi, Faculty of Materials Science and Engineering, 41 D. Mangeron Blvd., 700050, Iasi, \\ Romania \\ ${ }^{5}$ Romanian Inventors Forum, Str. Sf. P. Movila 3, 700089, Iasi, Romania
}

\begin{abstract}
The study compares flexural strength of single polymer polyester composites. Composites under examination had the form of laminates differing in the content of the reinforcement phase and the type of material subject to simulated absorption of distilled water and sea water. Simulation tests of distilled water and sea water absorption for single polymer polyester composites with $5 \%$ to $20 \%$ reinforcing phase were made in accordance with the PN-EN ISO 62:2008 standard. The determination of the measure of degradation of the composites, the magnitude of the bending stress, was conducted in accordance with the PN-EN ISO:178 standard. This work is part of a research relating to the quality and recycling of single polymer composite materials. The testing part of the research is aimed to define the properties of examined materials before they are used commercially in specific products.
\end{abstract}

Keywords: single polymer polyester composites, water absorption, degradation, flexural strength

Composites were used in the initial period of development of our civilization, but mass production of composites with the polymer matrix started in the second half of the 20th century. Dynamic growth of the polymer composite manufacturing was mainly spurred by the development of relevant polymer technologies as well as huge increase in demand for light and tough materials [15].

Polymer-matrix composites are essential in the production of wind turbines. The shipbuilding industry uses them for boat hulls, superstructures and fuel tanks. These materials, mainly polyester-glass composites, are also used in boatbuilding and machine industry $[1,6,7]$.

Due to the increasing use of polymer matrix composites confronted with the EU's environmental policy, the recycling of composite materials has become an important issue. Unfortunately, some polymer materials are not easy to be recycled [8-13]. The presence of additives or inclusions hinders the recycling process. In this connection, there is a demand for materials which at least consist of compatible polymer materials. To facilitate recycling, we propose an innovative use of reinforcement fibres made from the same material as the matrix, which results in a single polymer composite (SPC). Components in these materials may vary in molecular weight, density or degree of branching. Compared to conventional heterogeneous composite materials, an SPC has an extra advantage, i.e. homogeneity of chemical properties of the matrix and the reinforcement, that vary mainly in mechanical and thermal properties. This eliminates the need to separate them during recycling, which simplifies this process and reduces the associated adverse impact on the environment [1, 7-10, 14-20].

Single polymer composites are relatively new materials requiring research on their quality, microstructure, improvement of their properties to reduce the impact of external factors that might contribute to their degradation
$[6-9,21]$. Water is one of such factors. The impact of water may adversely affect strength properties of the tested materials, which undesirably limits the use of these materials in a humid environment, e.g. as support or insulating plates. The research discussed herein focuses on the impact of distilled and sea water absorption on flexural strength. Flexural strength may be a measure determining the degradation of single polymer polyester composites [15-21].

\section{Experiemntal part}

Materials and methods

The samples made of the composite materials, with components as presented in the table 1, were subjected to flexural strength tests. The three-point bending was assumed as a load scheme, in accordance with the PNEN ISO:178 standard (fig. 1). The test, conducted on the Instron-made equipment, was continued until the sample was destroyed (fractured). Based on the tests, maximum failure loads and bending stresses were calculated.

The bending theory developed for homogeneous and isotropic materials is applicable in evaluating inhomogeneous and strongly anisotropic materials. It is widely accepted also for testing composites [5-8]. Using the experimental data described above, flexural strength of the studied hybrid composites was determined, as the greatest value of the stress $\sigma_{f}$, from the following equation [6]:

$$
\sigma_{f}=\frac{3 F l}{2 b h^{2}}
$$

where:

$\sigma_{f}$ - bending stress [MPa], $F$ - applied force [N], I- support distance $[\mathrm{mm}], b$ - width of a sample [mm], $h$ - thickness of a sample [mm]. 
Bending strength tests are used in this work to describe the impact of water absorption on the quality of tested composite materials. The absorption of the water in the examined materials must be done in accordance with the PN-EN ISO 62:2008 standard [23]. To calculate the amount of absorbed water, the sample should be dried at $60^{\circ} \mathrm{C}$ for $24 \mathrm{~h}$, cooled in a desiccator and weighed to $0.1 \mathrm{mg}$ accuracy. The water absorption should be determined in distilled water or another liquid medium, using square samples with $100 \pm 1 \mathrm{~mm}$ sides, at temperatures 3, 23 and $100^{\circ} \mathrm{C}$. The samples should be weighed every 30 minutes until the mass reaches a stable value. The absorption of water will be calculated using this formula (2):

$$
c=\frac{m_{2}-m_{1}}{m_{1}} 100 \%
$$

where:

$c$ - absorption of liquid [\% weight]

$m_{1}$ - sample mass after drying $[\mathrm{g}]$

$m_{2}$ - mass of saturated sample [g]

One of the oldest ex situ methods of making SPCs was initiated by Capiati and Porter [2]. Advantages of this method include a relatively easy selection of the matrix and reinforcement materials, made of the same type of polymer, low production costs, possibility of using the reinforcing components in various forms: fibre, tape, yarn or fabric. This method can make use of many polymer materials to produce composites [1-7]. The reinforcement phase component is laid between two films made of the same polymer as the reinforcement, but having lower melt temperature. Thus prepared material is hot pressed under conditions allowing plasticizing the film without melting the reinforcement phase. The pressure must be sufficiently high for melted matrix polymer to completely fill the free spaces between the polyester fibres. Additionally, to avoid deterioration of the reinforcing fibre properties, the time of heating and cooling should be appropriately short [1-7].

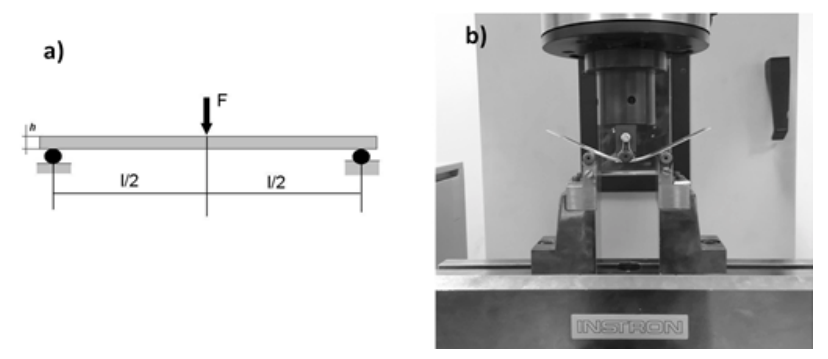

STAGES OF THE MANUFACTURING PROCESS

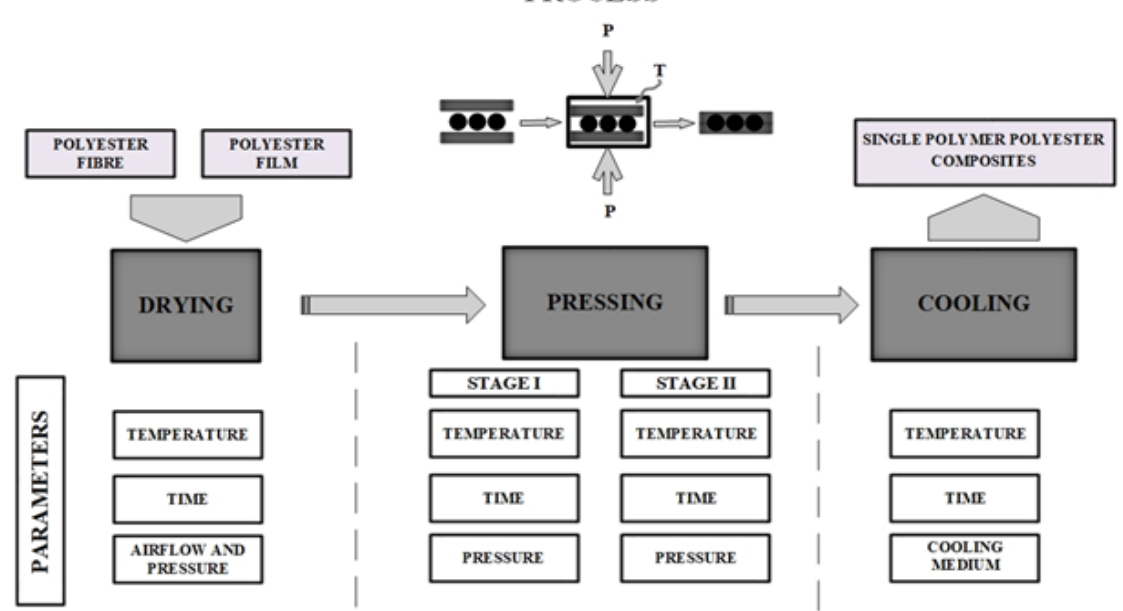

Fig.2. The schematic film stacking method of composite manufacturing
The process of composite production consists of the following technological stages (fig. 2): preparation of reinforcement and matrix phases, drying, pressing (two stages), cooling, removal of the product from the mould and finishing. Sheets produced in this way are subjected to the process of moulding to obtain the desired shape of a finished item. In addition, in order to avoid deterioration of properties of fibre reinforcement very short heating and cooling times should be used.

Single polymer polyester composites consisted of:

- reinforcement phase: stretched polyester fiber with enhanced strength and low shrinkage, purchased from Polish company TORLEN (fig. 3a).

- matrix material: colourless polyester film (PET-G) 0.5 mm thick, from VIVAK (fig. 3b).

Materials have been made by film-stacking method on the test bench at the Faculty of Mechanical Engineering and Mechatronics, West Pomeranian University of Technology in Szczecin. Then the single polymer polyester composite samples were treated in different conditions and, accordingly, grouped into three types:

- Sample type 1 - dried at $60^{\circ} \mathrm{C}$ for $24 \mathrm{~h}$, then cooled in a desiccator.

- Sample type 2 - dried at $60^{\circ} \mathrm{C}$ for $24 \mathrm{~h}$, then cooled in a desiccator and weighed to the nearest $0.1 \mathrm{mg}$, then immersed in distilled water having a temperature of $23^{\circ} \mathrm{C}$ for $60 \mathrm{~h}$.

- Sample type 2 - dried at $60^{\circ} \mathrm{C}$ for $24 \mathrm{~h}$, then cooled in a desiccator and weighed to the nearest $0.1 \mathrm{mg}$, then subjected to the action of sea water having a temperature of $23^{\circ} \mathrm{C}$ for $60 \mathrm{~h}$.

Table 1 presents the determined material component quantities depending on the type of simulation and the content of reinforcement.

The said standard recommends using samples with the length/height ratio $\mathrm{l} / \mathrm{h}=16$. Average values of the height (h) corresponding with the number of layers of the reinforcing material in the laminates are shown in table 2. This condition ensures that a destruction through the

Fig 1. Scheme of the sample loading method and location of the force $F$ in the three-point bending test [22] a) scheme, b) real study

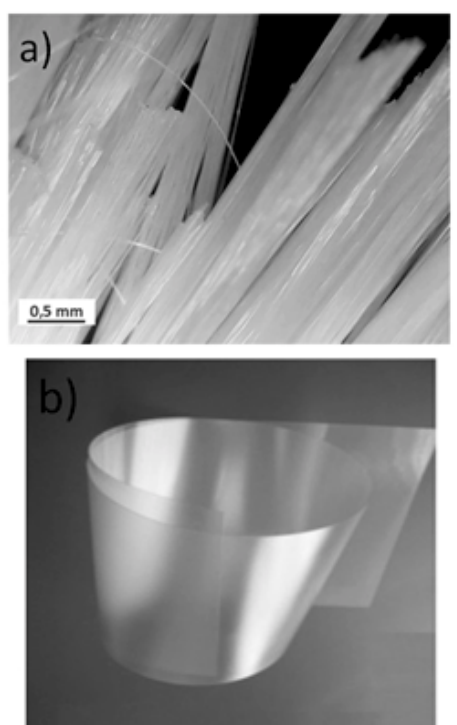

Fig. 3. Components used for a single-polymer composite material: a) reinforcement; b) matrix 


\begin{tabular}{|c|c|c|c|}
\hline MATERIAL ID & MATRIX & REINFORCEMENT & SAMPLE TYPE \\
\hline A1 & PETG & - & type 1 \\
\hline B1 & PETG & $5 \%$ PET, ordered fibres & type 1 \\
\hline C1 & PETG & $10 \%$ PET, ordered fibres & type 1 \\
\hline D1 & PETG & $15 \%$ PET, ordered fibres & type 1 \\
\hline E1 & PETG & $20 \%$ PET, ordered fibres & type 1 \\
\hline A2 & PETG & & type 2 \\
\hline B2 & PETG & $5 \%$ PET, ordered fibres & type 2 \\
\hline C2 & PETG & $10 \%$ PET, ordered fibres & type 2 \\
\hline D2 & PETG & $15 \%$ PET, ordered fibres & type 2 \\
\hline E2 & PETG & $20 \%$ PET, ordered fibres & type 2 \\
\hline A3 & PETG & & type 3 \\
\hline B3 & PETG & $5 \%$ PET, ordered fibres & type 3 \\
\hline C3 & PETG & $10 \%$ PET, ordered fibres & type 3 \\
\hline D3 & PETG & $15 \%$ PET, ordered fibres & type 3 \\
\hline E3 & PETG & $20 \%$ PET, ordered fibres & type 3 \\
\hline & & &
\end{tabular}

Table 1

THE SINGLE POLYMER COMPOSITE DATA

Table 2

AVERAGE THICKNESS OF THE SAMPLES, CORRESPONDING TO THE REINFORCEMENT WEIGHT FRACTION

\begin{tabular}{|c|c|c|c|c|c|c|c|c|c|c|c|c|c|c|c|}
\hline $\begin{array}{l}\text { 目 } \\
\text { 堂 } \\
\text { 孚 } \\
\text { 壱 }\end{array}$ & 7 & $\overline{\mathscr{M}}$ & $\vec{U}$ & $\vec{\theta}$ & 四 & $\frac{3}{4}$ & ติ & $\mathcal{U}$ & 苂 & 矛 & $\frac{m}{4}$ & $\tilde{m}$ & 3 & ค̆ & య્ઞ \\
\hline 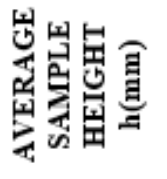 & 'م & $\stackrel{\infty}{\circ}$ & $\stackrel{\text { So }}{-}$ & $\stackrel{\infty}{\circ}$ & $\stackrel{J}{\leftrightarrows}$ & ஃ̊ & $\stackrel{\infty}{\circ}$ & $\stackrel{\text { g }}{-}$ & $\exists$ & $\stackrel{9}{\leftrightarrows}$ & '̊̀ & $\stackrel{\infty}{\circ}$ & $\stackrel{\text { Sิ }}{\circ}$ & $\stackrel{8}{\circ}$ & $\underset{ت}{\Xi}$ \\
\hline
\end{tabular}

normal stresses related to the bending moment will occur before delamination as a result of the shearing stress [611].

\section{Results and discussions}

Figure 4 illustrates the absorption of distilled / sea water for two types of composite materials ( 2 and 3 ).

Polyethylene terephthalate glycol modified (PETG) is characterized by low water absorbency. It follows from the manufacturer's information [1-4] that the absorption of water having a temperature of $17^{\circ} \mathrm{C}$ by PETG can be

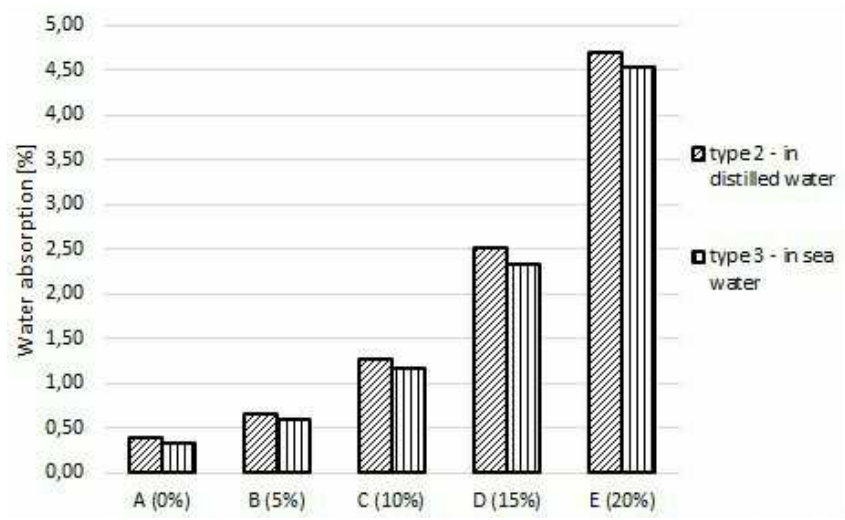

Fig. 4. Water absorption (distilled and sea water) in the tested composites approximately $0.2 \%$ (measured at total immersion of the sample). Therefore, the obtained quantities of water absorption $0.33 \% ; 0.38 \%$ obtained from tests at room temperature $\left(23^{\circ} \mathrm{C}\right)$ for pure material $(A 2, A 3)$ of the matrix seem to be justified.

It is also evident (fig. 4) that the presence of PET fibres in the matrix increases the absorption of water in the composite, and that increase is proportional to the mass of the reinforcement phase. Water diffusion across the interfacial boundary is facilitated by its incoherence. It can be noted from the results that materials submerged in sea water have lower absorbency than in distilled water by $6 \%$ in the case of pure PETG (A2 and A3) and by approximately $13 \%$ (B) in the case of the composite material. These differences are most likely due to the inhibition of water absorption by the $\mathrm{NaCl}$ contained in sea water.

Figure 5 presents values of the bending stresses for composites with different proportions of reinforcement phase and different samples (type 1-3). It follows from an analysis of figure 5 that modifying materials by adding PET fibers improves their mechanical properties. The bending stresses increase along with added quantity of the reinforcement phase. Adding $5 \%$ weight of fibres increases the flexural strength of the test material by $10 \%$. The greatest flexural strength is presented by composites with matrix modified by adding 20\% weight reinforcement phase - PET fibers. In case of this material (E1-3), approx. $42 \%$ increase of strength can be observed in comparison 


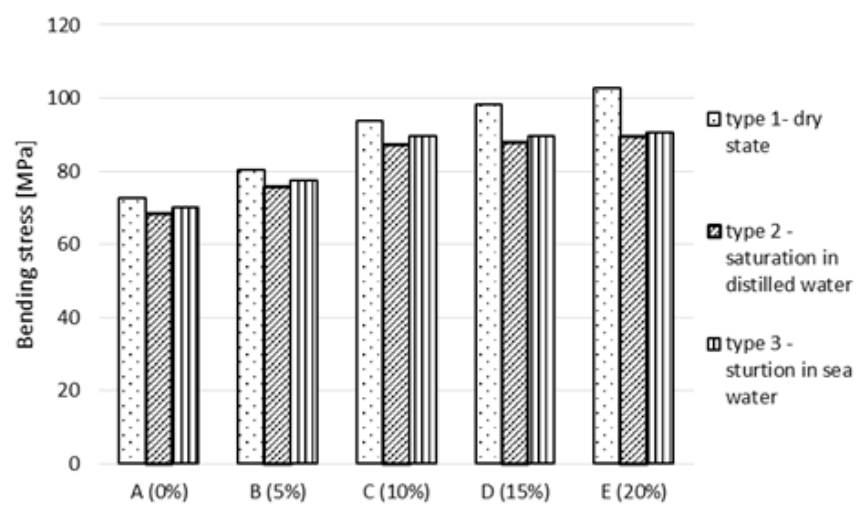

Fig. 5. Comparison of bending stresses for composites with different proportions of the reinforcement phase (material IDs according to the table 1)

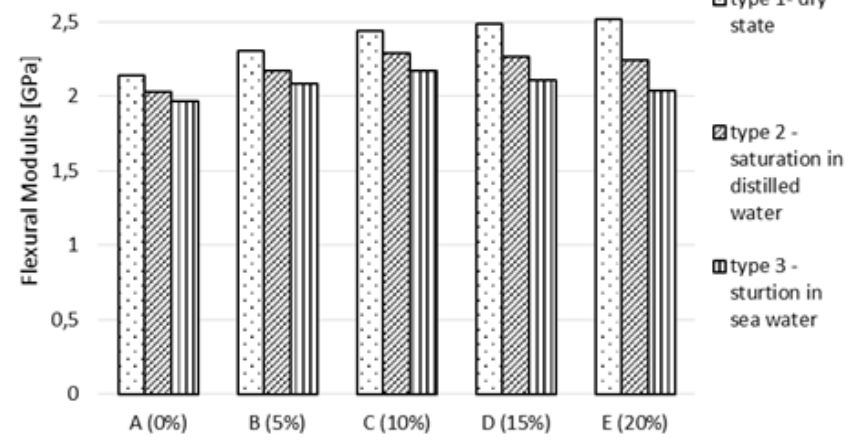

Fig. 6. Comparison of the flexural modulus for composites with different proportions of the reinforcement phase (material IDs according to table 1)
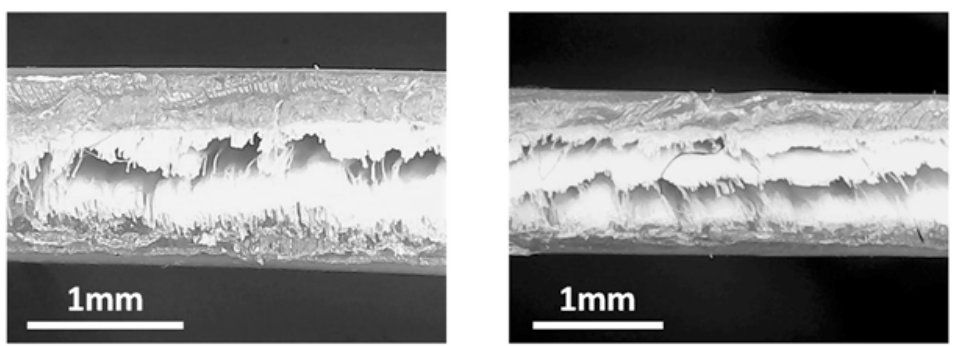

Fig.7. An example of single polymer composite microstructure degradation caused by water absorption.

to a composite without PET fibers. Increase of the modifying filler up to $20 \%$ was impossible using that particular manufacturing process.

Figure 6 presents values of the flexural modulus for composites with different proportions of the reinforcement phase. Like in the case of bending stresses, we can state that the greatest strength is demonstrated by composites with the matrix modified with 20\% PET fiber addition. However, in the case of this composite (E1), 17\% increase in the modulus can be observed in comparison with the non-modified materials.

\section{Conclusions}

The largest decrease in flexural strength was observed in the composite E2, as much as 15\% compared to the identical composite in the dry state (E1).

To characterize the process and extent of composite degradation caused by water, once the dynamics of water diffusion in the material are defined, we determine the decrease in mechanical properties, in this case flexural strength and rigidity (Young's modulus). These changes resultfrom microstructural degradation thatmanifests itself by separation of reinforcing fibres from the matrix (fig. 7) and interfacial cracks.

This is most likely due to water absorption by fibers and consequent change in their dimensions as a result of swelling, and the different water absorbency characterizing the matrix and the reinforcement, which causes interfacial boundary stresses. Visible defects [24] existing in water saturated material significantly accelerate destructive processes occurring under load. It follows from the research that flexural strength may provide a measure of single polymer composite degradation.

\section{References}

1.KMETTY, A., BARANY, T., KARGER-KOCSIS, J., Progress in Polymer Science, 35, 2010, p. 1288-1310

2.CAPIATI, N.J ., PORTER, R.S.; J . Mater. Sci., 10, 1975, p. 1671-1677.

3.KARGER-KOCSIS, J., BARANY, T., Composites Science and Technology, 92, 2014, p. 77-94.
4.SHUBHRA Q.T.H., ALAM A., GAFUR M., SHAMSUDDIN S., KHAN M., SAHA M., SAHA D., QUAIYYUM M., KHAN J ., ASHADUZZAMAN M., Fibers and Polymers 2010;11:725-31.

5.BRYLL. K, PIESOWICZ E., GAWDZIÑSKA K., IRSKA I., KWIECINSKA

B.; Inzynieria Materia ${ }^{3}$ owa, 2015, 6(208), 344-347.

6. HUGHES M., HILL C., SEBE G. , HAGUE J., SPEAR M. and MOTT L., Composite Interfaces 7 (2000) 13.

7.MATABOLA K.P., DE VRIESA.R., MOOLMAN F.S., LUYT A.S; J MaterSci 2009; 44(23):6213-22.

8.ANDRZEJ EWSKI J.: Processing and properties of single polymer polyester composites - PhD thesis, Poznan University of Technology, Poznan 2014 (in Polisch).

9.KOZIOL M.; Kompozyty 10: 4 (2010); s. 317-321.

10.THWE MM, LIAO K., Compos Part A 2002;33:43-52.

11.BISMARCK A., ASKARGORTA I.A., SPRINGER J., LAMPKE T., WIELAGE B., STAMBOULIS A., et al., Polym Compos 2002;23:872-94. 12.GADEK-MOSZCZAK A., ZMUDKA S., Stereology and image analysis in material science Book Series: Solid State Phenomena 2012, Volume: 197 Pages: 186

13.REDDY R.C., SARDASHTI A.P., SIMON LC., Composites Science and Technology 2010;70:1674-80.

14.ENTWISTLE K. M. and TERRILL N. J., J. Mater. Sci. 35 (2000) 1675. 15.DUFRESNE A., Compos. Interfaces 7 (2000) 53.

16.STAMBOULIS A, BAILLIE CA, PEIJS T., Compos Part A Appl Sci Manuf 2001;32:1105-15.

17.BRYLL, K., GAWDZINSKA, K., NABIALEK, M., PAWLOWSKA, P., Rev. Chim.(Bucharest), 68, no.9, 2017, in press

18.SUBLI, M.H., OMAR, M.F., SANDU, I.G., ZULKEPLI, N.N., ABDULLAH, M.M.A., SANDU, A.V., Mat. Plast., 51, no. 4, 2014, p. 391.

19.J AYA, H., OMAR, M.F., AKIL, H.M., AHMAD, Z.A., ZULKEPLI, N.N., ABDULLAH, M.M.A., SANDU, I.G., VIZUREANU, P., Mat. Plast., 53, no. 1, 2016, p. 85.

20.BOJ AN, A.C., POPA, A.G., PUSKAS, A., 10TH International Conference Interdisciplinarity In Engineering, INTER-ENG 2016, vol 181, 2017, p. 712-717.

21.BRONIEWSKI T., KAPKO J., PLACZEK W., THOMALLA, Testing and evaluation of the properties of plastics, Warszawa WNT, 2000.

22.*** PN EN ISO 178 Plastics - Determination of flexural properties 23.*** PN-EN ISO 62:2008 Plastics - Determination of water absorption. 24.GAWDZIÑSKA K., Archives Of Metallurgy And Materials, Volume: 58, Issue: 3, 2013, pp: 659-662, DOI: 10.2478/amm-2013-005.

Manuscript received: 15.03 .2017 